\title{
New Polymeric Admixture for Cement Based on Hyperbranched Poly Amide-Ester with Pentaerythritol Core
}

\author{
Amal Amin Ibrahim, ${ }^{1}$ Ahmed El-Sayed Abdel-Megied, ${ }^{2}$ Mohamed Sayed Selim, ${ }^{3}$ \\ Hassan Hassenen Darweesh, ${ }^{4}$ and Magdy Mohamed Ayoub ${ }^{1}$ \\ ${ }^{1}$ Polymers and Pigments Department, National Research Center, Dokki, Giza, Egypt \\ ${ }^{2}$ Organic Chemistry Department, Menoufiya University, Shebin El-Kom, Egypt \\ ${ }^{3}$ Petroleum Application Department, Egyptian Petroleum Research Institute, Nasr City, Cairo 11727, Egypt \\ ${ }^{4}$ Department of Refractories, Ceramics and Building Materials, National Research Center, Dokki, Giza, Egypt
}

Correspondence should be addressed to Amal Amin Ibrahim; aamin_07@yahoo.com

Received 17 March 2013; Accepted 14 April 2013

Academic Editors: Y. Hiraoka, Y. Nakayama, and J. Provis

Copyright (C) 2013 Amal Amin Ibrahim et al. This is an open access article distributed under the Creative Commons Attribution License, which permits unrestricted use, distribution, and reproduction in any medium, provided the original work is properly cited.

\begin{abstract}
Hyperbranched poly amide-ester (HBPAE) was synthesized by a solution condensation polymerization through one-step process using pentaerythritol as a central core and $\mathrm{AB}_{2}$ prepolymerized monomer which was rapidly prepared at room temperature $\left(25^{\circ} \mathrm{C}\right)$ using commercially available maleic anhydride (MA) and diethanolamine (DEA) monomers in the presence of p-toluene sulfonic acid as a catalyst. The prepared polymer was characterized by GPC, IR, ${ }^{1} \mathrm{H}-\mathrm{NMR}$, and thermal analysis (TGA and DSC). The influence of the polymer addition to the cement paste was investigated by measuring the effect of 1,3 and $5 \mathrm{wt} \% \mathrm{HBPAE}$ solutions on the properties of ordinary portland cement (OPC). Accordingly, several parameters were investigated such as water of consistency, setting times, bulk density, apparent porosity, compressive strength, and combined water content of the polymer/cement pastes. The SEM images proved that the incorporation of HBPAE with the OPC cement did not affect the chemical composition of hydrates, but it only affected the physical state, shape, size, morphology, and crystallinity of the formed hydrates. The results showed that the polymer addition to OPC pastes improved the physicomechanical properties of cement.
\end{abstract}

\section{Introduction}

In the recent years, significant efforts have been focused on synthesis and application of the hyperbranched polymers as they exhibit many special merits such as highly branched three-dimensional globular architecture, low viscosity, high solubility, abundance of functional end groups, and internal cavities in the molecule, which can be easily designed to meet specific needs in various applications [1-3].

Hyperbranched polymers can be easily prepared in one-step reactions and typically have randomly distributed branches that make them attractive alternatives for numerous applications in comparison with their regular counterparts (dendrimers) which need more expensive and drastic conditions to be properly prepared [4-6].
Hyperbranched polymers are potentially applied in various fields from drug delivery to coatings where increasing scientific interest for them over the past several decades is evident and confirmed by the increasing number of publications [7-12].

The concept of the polymer modification for the cement mortars and concretes is not new, since a considerable research and development of a polymer modification have been performed for the past decades [13, 14]. Consequently, various polymer-based admixtures have been developed to produce the currently popular construction materials because of their good cost-performance balance [15]. The addition of concrete admixtures is a frequently used application in the concrete production, recent studies of which proved their favorable effects on the characteristics of 
TABLE 1: Chemical composition of the used OPC cement, wt $\%$.

\begin{tabular}{lccccccccc}
\hline Materials oxides & L.O.I & $\mathrm{SiO}_{2}$ & $\mathrm{Al}_{2} \mathrm{O}_{3}$ & $\mathrm{Fe}_{2} \mathrm{O}_{3}$ & $\mathrm{CaO}$ & $\mathrm{MgO}$ & $\mathrm{Na}_{2} \mathrm{O}$ & $\mathrm{K}_{2} \mathrm{O}$ & $\mathrm{SO}_{3}$ \\
\hline OPC & 2.64 & 20.12 & 5.25 & 3.38 & 63.13 & 1.53 & 0.55 & 0.3 & 2.54 \\
\hline
\end{tabular}

concrete [16-20]. The use of admixtures becomes inevitable in terms of saving time and improving the characteristics of both fresh and hardened concretes [21] such as workability, resistance against physical and chemical external effects, and being economical.

Nowadays, hyperbranched polymers are successfully employed in the building industry as cement admixtures due to their extraordinary desirable properties [22].

Accordingly, this paper investigated the influence of using hyperbranched poly amide-ester (HBPAE) derived from maleic anhydride, diethanolamine, and pentaerthritol as a new polymeric cement admixture on the physicomechanical characteristics of the modified cement pastes.

\section{Materials and Methods}

2.1. Chemicals and Materials. Diethanolamine (DEA), maleic anhydride (MA), p-toluene sulfonic acid (p-TSA), and pentaerithritol (PER) were delivered from Fluka Chemicals, and $\mathrm{N}, \mathrm{N}^{\prime}$-dimethylformamide (DMF) was supplied from Sigma Aldrich Chemicals. The OPC with a surface area of $3300 \mathrm{~cm}^{2} / \mathrm{g}$ was delivered from El-Masria Cement Company, Egypt. The chemical composition of OPC is listed in Table 1.

2.2. Instrumentation and Measurements. The prepared polymer was characterized via different investigation techniques such as infrared spectra (IR), gel permeation chromatography (GPC), nuclear magnetic resonance ( $\left.{ }^{1} \mathrm{HNMR}\right)$, and thermal analyses such as thermal gravimetric analyses (TGA) and differential scanning calorimetry (DSC). IR spectra were recorded by FTIR-JASCO in the range of $4000-400 \mathrm{~cm}^{-1}$. The samples were pressed into potassium bromide $(\mathrm{KBr})$ pellets. The gel permeation chromatography (GPC) measurements were carried out using GPC-1100 Agilent technologies with reactive index detector with $100-10^{4}-10^{5} \mathrm{~A}^{\circ}$ Ultrastyragel columns connected in series using polystyrene (PS) as standard and $\mathrm{N}, \mathrm{N}^{\prime}$-dimethylformamide (DMF) as eluent where the number average molecular weight $\left(\bar{M}_{n}\right)$ and polydispersity $\left(\bar{M}_{w} / \bar{M}_{n}\right)$ values were determined.

${ }^{1}$ HNMR spectrum was obtained by Varian Mercury $300 \mathrm{MHz}$, using tetramethylsilane (TMS) as internal standard and DMSO as the main solvent. TGA was carried out by using TGA-50 shimadzu instrument, in the range $40-400^{\circ} \mathrm{C}$; the heating rate was $10 \mathrm{~K} / \mathrm{min}$ and under nitrogen atmosphere. The DSC measurement was carried out by using differential scanning calorimeter DSC-60 shimadzu in the range from $20^{\circ} \mathrm{C}$ to $140^{\circ} \mathrm{C}$, with a scanning rate of $20 \mathrm{~K} / \mathrm{min}$, and under nitrogen atmosphere.

\subsection{Test Methods of the Cement Samples}

2.3.1. Water of Consistency and Setting Time. Standard Vicat apparatus was used to determine the water of consistency (w/c) as a standard measure of plasticity of a cement paste. Setting times were performed at $28 \pm 2^{\circ} \mathrm{C}$ according to ASTM specification $[23,24]$.

2.3.2. Bulk Density and Apparent Porosity. Bulk density (B. D.) and apparent porosity (A. P.) of the hardened cement pastes [25] were calculated from the following equations:

$$
\begin{aligned}
& \text { B. D. }\left(\mathrm{g} / \mathrm{cm}^{3}\right)=\frac{W_{1}}{W_{1}-W_{2}} \times 1, \\
& \text { A. P. }(\%)=\frac{W_{1}-W_{3}}{W_{1}-W_{2}} \times 100,
\end{aligned}
$$

where $W_{1}$ is saturated weight, $W_{2}$ is suspended weight and $W_{3}$ is dry weight, of the cement paste samples.

2.3.3. Compressive Strength. Compressive strength [26] was carried out by using a hydraulic testing machine of the type LPM $600 \mathrm{M}_{1}$ SEIDNER (Germany) having a full capacity of $600 \mathrm{KN}$. The loading was applied on one inch cubic samples perpendicular to the direction of the upper surface of the polymer/cement samples.

2.3.4. Chemically Combined Water Content. The chemically combined water content at each time interval was also determined on the basis of ignition loss [27] using the following equation:

$$
W_{n}=W_{1}-\frac{W_{2}}{W_{2}} \times 100
$$

where $W_{1}$ is Weight before ignition, $W_{2}$ is ignited weight and $W_{n}$ is combined water of the cement paste samples.

\subsection{Synthesis of Hyperbranched Poly Amide-Ester (HBPAE)}

2.4.1. Synthesis of $A B_{2}$ Monomer. $\mathrm{AB}_{2}$ monomer was prepared by amidation reaction of $\mathrm{DEA}$ and $\mathrm{MA}$ at a molar ratio of $1 / 1$ where $0.1 \mathrm{~mol}$ of MA was dissolved in $(100 \mathrm{~mL})$ of chloroform in three-necked round-bottom flask at $25^{\circ} \mathrm{C}$. $0.1 \mathrm{~mol}$ of crystal DEA was rapidly poured into MA solution. The reaction mixture was stirred with a magnetic stirrer at $60^{\circ} \mathrm{C}$ under reflux for $4 \mathrm{~h}$ and under nitrogen to obtain the $\mathrm{AB}_{2}$ monomer.

2.4.2. Synthesis of HBPAE. The prepared hyperbranched poly amide-ester as shown in Scheme 1 was synthesized through pseudo-one-step process where $0.4 \mathrm{~mol}$ of the previously prepared $\mathrm{AB}_{2}$ monomer solution, $0.1 \mathrm{~mol}$ of pentaerithritol and $0.5 \mathrm{wt} \%$ of p-TSA catalyst were introduced, respectively, to $250 \mathrm{~mL}$ three-necked flask. Vacuum pump and a reflux distillation equipment with water condenser were installed. The flask was put into an oil bath adjusted at constant temperature of $120^{\circ} \mathrm{C}$. The mixture was stirred with a magnetic stirrer 
<smiles>O=C1C=CC(=O)C1</smiles>

Maleic anhydride (MA)

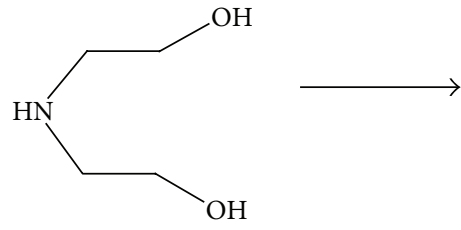

Diethanolamine (DEA)<smiles>O=C(O)/C=C\C(=O)N(CCO)CCO</smiles>

$\mathrm{AB}_{2}$ monomer

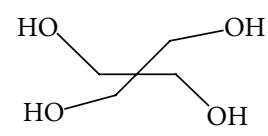

Pentaerythritol (PER)

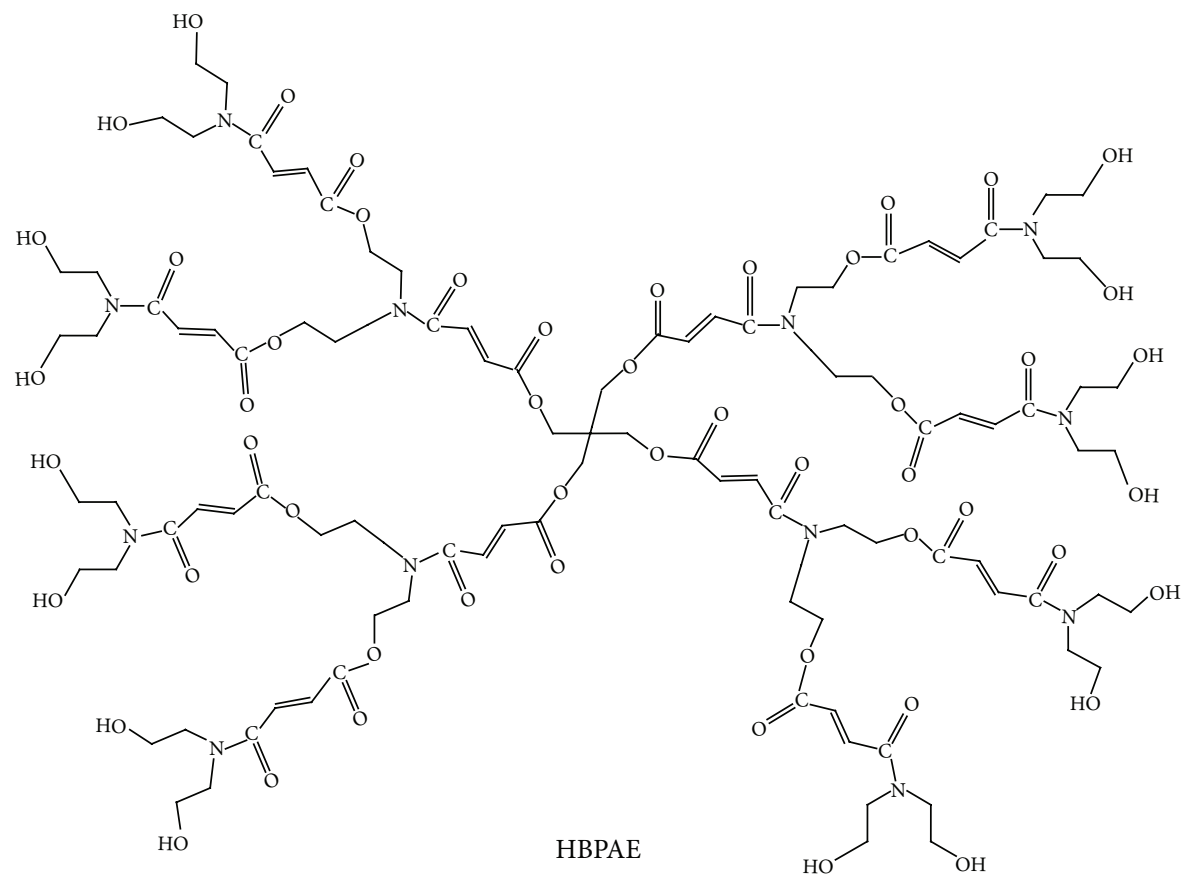

Scheme 1: Synthesis of hyperbranched poly amide-ester.

for $6 \mathrm{~h}$ under vacuum conditions. The crude products were dissolved in $(100 \mathrm{~mL})$ DMF, then precipitated, and washed by a mixture of solvents of ethyl ether/acetone (1/1). The precipitate was dried in vaccum.

2.4.3. Preparation of Cement Mixes. For the preparation of cement samples, three different polymer solutions with variable concentrations were prepared such as $1 \%, 3 \%$, and $5 \%$. Each solution was mixed separately with ordinary Portland cement to study its performance on the properties of the cement pastes.

Water of consistency and setting time measurements were carried out on the blank-cement samples of each type by adding water gradually to cement and testing it with Vicat apparatus. The same procedure was repeated by adding the polymer solutions instead of water to study the effect of adding the polymer.

Cubic samples of blank and polymer/cement admixtures were made and immersed in water basin for different time periods (1, 3, 7, and 28 days); then they were subjected to be tested for compressive strength, bulk density, apparent porosity, and chemically combined water content for these samples.

\section{Results and Discussion}

The hyperbranched polymer (HBPAE) was synthesized via pseudo-one-step reaction between pentaerithritol as a central core and $\mathrm{AB}_{2}$ prepolymerized monomer (Scheme 1) [28]. The HBPAE was characterized by GPC, IR, ${ }^{1} \mathrm{HNMR}$, TGA, and DSC. IR spectrum of the prepared polymer as in Figure 1 revealed the appearance of strong absorption band of hydroxyl group at $3413 \mathrm{~cm}^{-1}$, ester group stretching at $1728 \mathrm{~cm}^{-1}$ and the absorption band of amide carbonyl groups at $1644 \mathrm{~cm}^{-1}$. The band at $1050 \mathrm{~cm}^{-1}$ was attributed to $=\mathrm{C}-$ $\mathrm{H}$ bending and those at 1127,1174 , and $1293 \mathrm{~cm}^{-1}$ were attributed to $\mathrm{C}-\mathrm{O}$ and $\mathrm{C}-\mathrm{N}$ stretches. ${ }^{1} \mathrm{H}-\mathrm{NMR}$ spectrum of HBPAE showed, as in Figure 2, distinguished signals of 


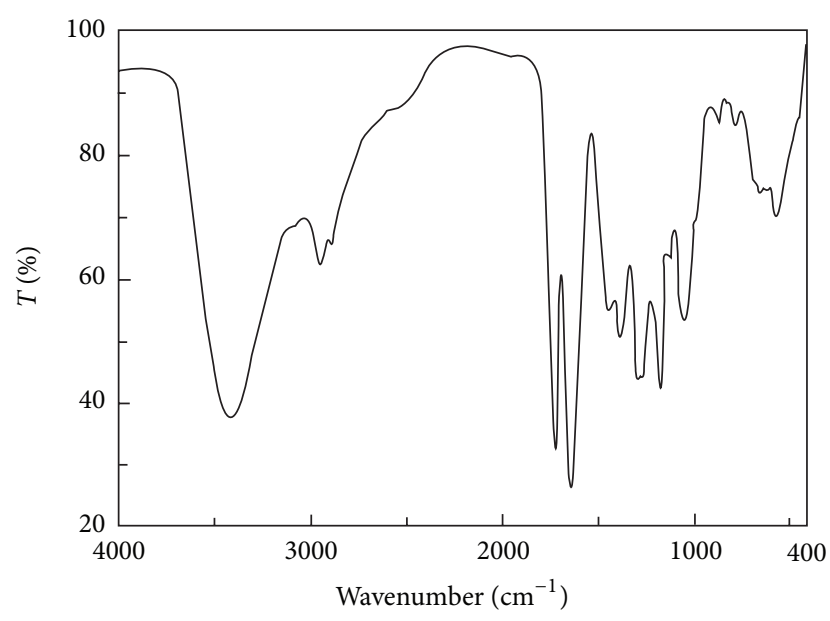

FIGURE 1: IR spectrum of the hyperbranched poly amide-ester.

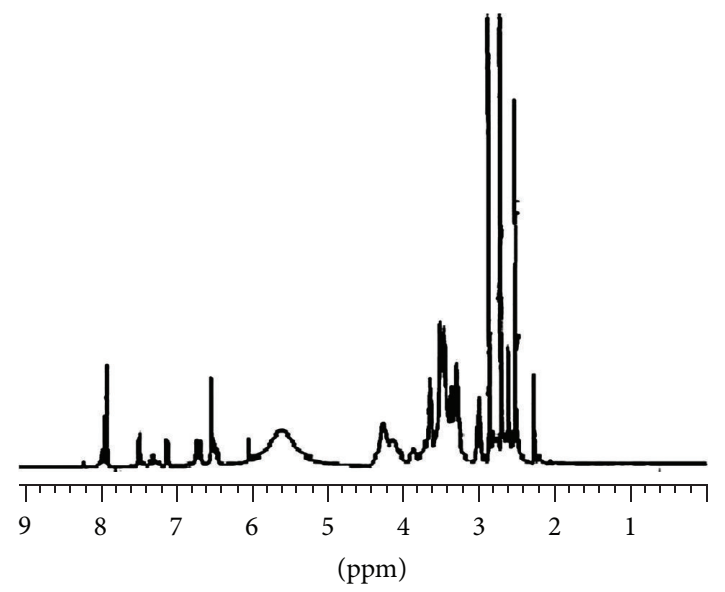

FigURE 2: ${ }^{1}$ HNMR spectrum of the prepared hyperbranched poly amide-ester.

chemical shifts $(\delta, \mathrm{ppm})$ at $2.5-3.2,3.5-4.1,4.2-4.5,4.6$ and 6.5 which were referred to $\left(\mathrm{O}-\mathrm{CH}_{2} \mathrm{CR}_{3} ; \mathrm{R}=\mathrm{CH}_{2}-\right.$ $\left.\mathrm{OCO}-\mathrm{N}\left(\mathrm{CH}_{2} \mathrm{CH} 2\right)_{2} \mathrm{OCO}-\right),\left(\mathrm{O}=\mathrm{CN}-\mathrm{CH}_{2}\right),\left(\mathrm{O}=\mathrm{CO}-\mathrm{CH}_{2}\right)$, $\left(-\mathrm{CH}_{2} \mathrm{CH}_{2} \mathrm{OH}\right)$, and the protons of alkenes. TGA of HBPAE, as shown in Figure 3, exhibited excellent thermal stability. The weight loss was just $10 \%$ up to $176.4^{\circ} \mathrm{C}$. The weight losses reached $20 \%$ when the temperature was raised to $200^{\circ} \mathrm{C}$. TG curve of the hyperbranched poly amide-ester descended when the temperature reached the range of $220-250^{\circ} \mathrm{C}$. This behavior might be due to the decomposition of amine and ester bonds in the hyperbranched poly amide-ester. DSC measurements recorded $T_{g}$ value as $72.22^{\circ} \mathrm{C}$. The GPC results indicated the number average molecular weight of HBPAE as $3578 \mathrm{~g} / \mathrm{mol}$ and the polydispersity value as 2.83 .

The prepared hyperbranched HBPAE polymer was tested in cement as a new application where several parameters were measured such as water of consistency, setting times, bulk density, apparent porosity, and compressive strength.

The water of consistency as well as setting times (initial and final) of the OPC cement pastes premixed with variable

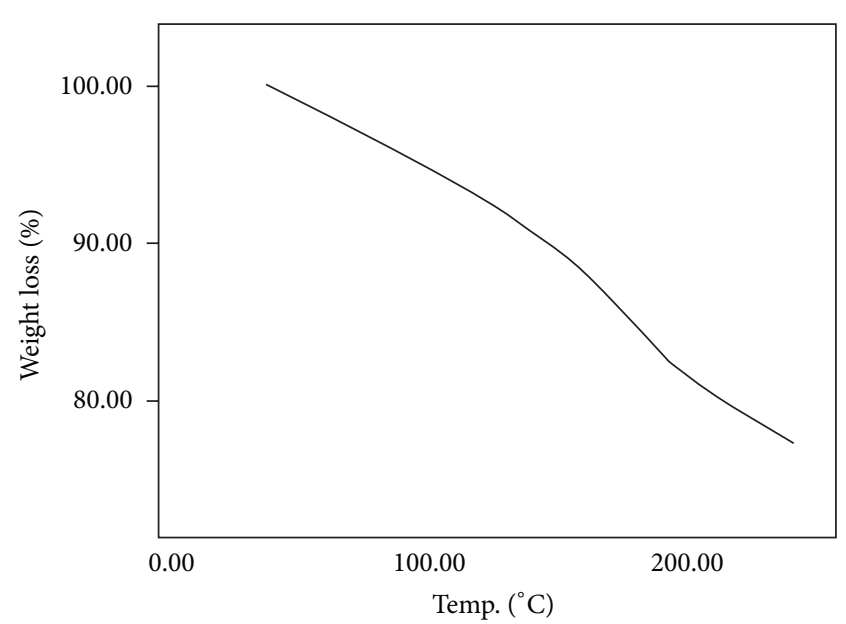

FIGURE 3: TGA of the prepared hyperbranched poly amide-ester.

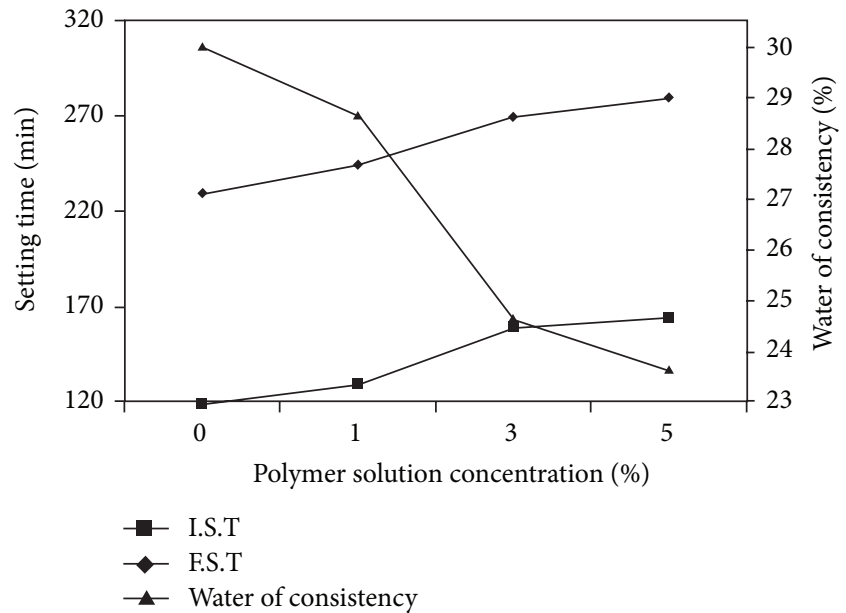

FIGURE 4: Water of consistency and setting times (initial and final) measurements of OPC premixed with $1 \%, 3 \%$, and $5 \%$ of HBPAE.

concentrations of HBPAE are represented in Figure 4. Generally, the water of consistency gradually decreased with increasing the polymer content up to $5 \%$. Using polymer concentration of $5 \%$, the water of consistency decreased from $30 \%$ to $23.33 \%$ for OPC. The water of consistency was highly reduced by $5.34-6.76 \%$ for OPC, when compared with that of the blank. So, it was concluded that this polymer acted as water reducer [29]. Although the polymer lowered the water of consistency, it increased the setting times (initial and final). The initial and final setting times increased from 120 to 165 minutes and 230 to 280 minutes with increasing HBPAE concentration. This behavior meant that the HBPAE behaved as a retarder. The reduction in water of consistency and the elongation of setting times at the same time were attributed to the adsorption of the highly polar polymer molecules on the cement particles and hence the subsequent formation of a polymer film. An electrostatic repulsion between the negatively charged cement particles formed, which reduced the interparticle attraction between the cement particles 


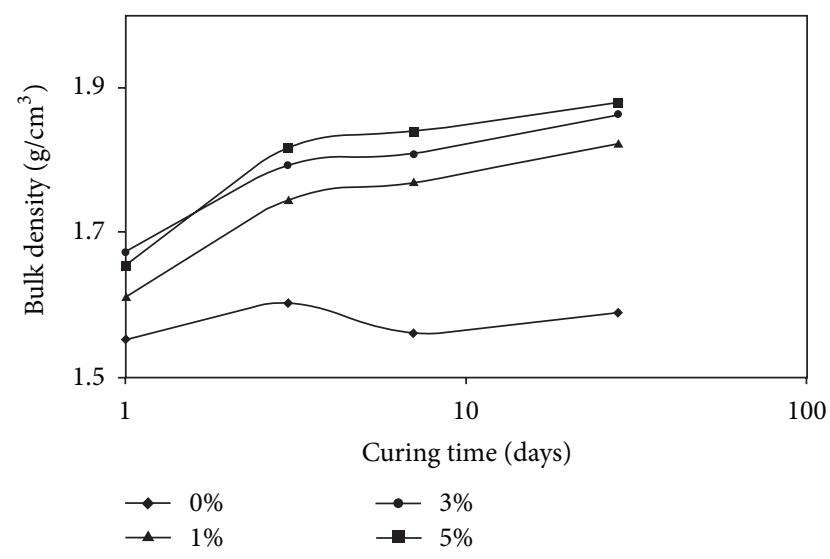

FIGURE 5: Bulk density of OPC cement pastes premixed with $1 \%, 3 \%$, and $5 \%$ HBPAE.

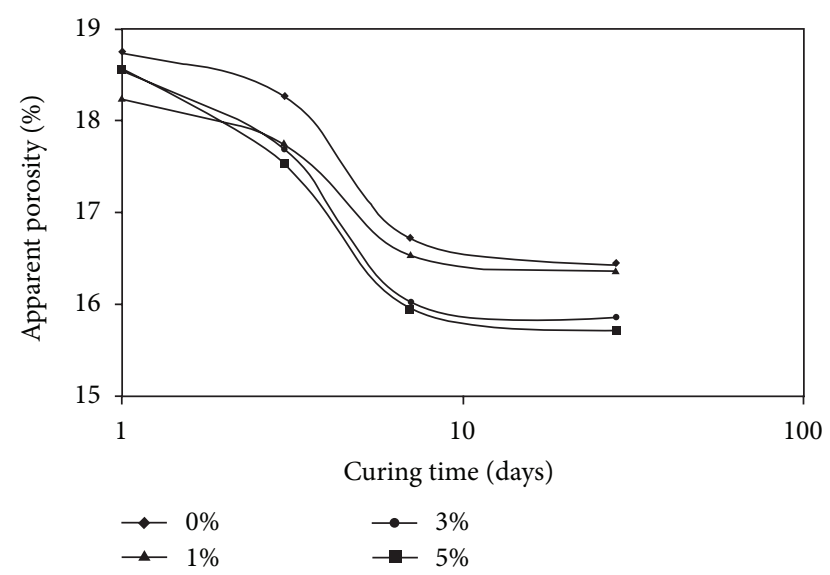

FIGURE 6: Apparent porosity of OPC cement pastes premixed with $1 \%, 3 \%$, and $5 \%$ HBPAE.

and then prevented flocculation or agglomeration for them. That partial or full encapsulation of cement hydrates by the polymer molecules retarded the hydration process. So, the used polymer acted as a water reducing admixture and also as a setting retarder.

The bulk density and the apparent porosity are plotted as a function of curing time in Figures 5 and 6, respectively. Generally, the bulk density of all cement mixes increased gradually with curing time while the apparent porosity decreased. This is mainly due to the continual deposition of the formed hydration products in the pore structure of the hardened cement pastes. Thus, the apparent porosity decreases, and hence the bulk density enhances. Moreover, the bulk density was further improved with increasing the polymer concentration. The higher density values with HBPAE may be attributed to the improvement in the hydration process and subsequently the increase in the hydration products compared with those of blank samples.

The chemically combined water contents of OPC cement pastes premixed with $1 \%, 3 \%$ and $5 \%$ HBPAE are represented as a function of polymer concentration as in Figure 7. The combined water contents of all cement pastes are generally

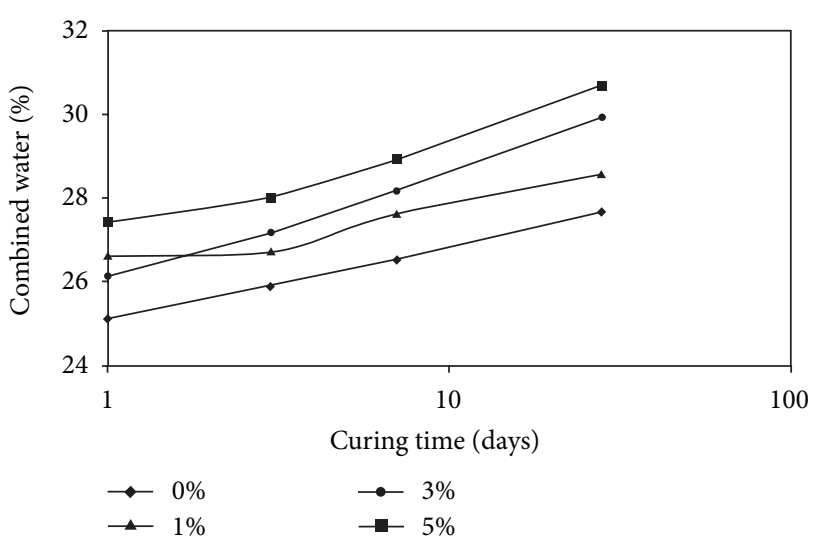

FIGURE 7: Chemically combined water contents of OPC cement pastes premixed with $1 \%, 3 \%$, and $5 \%$ HBPAE.

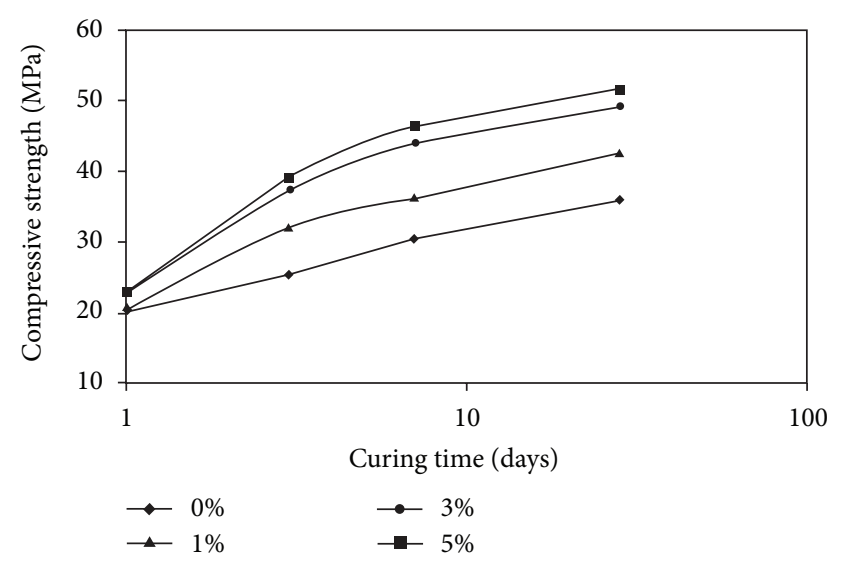

FIGURE 8: Compressive strength measurements of OPC pastes and those premixed with $1 \%, 3 \%$, and $5 \%$ of HBPAE up to 28 days.

increased with curing time up to 28 days. This is mainly attributed to the gradual and continuous formation of hydration products resulting from the hydration of the main phases of cement, particularly $\mathrm{C}_{3} \mathrm{~S}$ and $\beta-\mathrm{C}_{2} \mathrm{~S}$. The combined water contents increased with polymer concentration. The higher values of combined water contents by incorporation of small amounts of polymer with OPC are due to the dispersion effect of the polymer on the cement grains, which in turn prevents their aggregation and thus improves the hydration process [30].

The compressive strength of OPC cement pastes premixed with $1 \%, 3 \%$ and $5 \%$ HBPAE was plotted as a function of curing time as shown in Figure 8. The compressive strength of the hardened cement pastes generally increased with curing time. This is mainly due to the continual formation of the hydration products which deposited into the pores of the cement pastes. Thereby, the apparent porosity decreased gradually and the compactness increased. Hence, the bulk density increased by time of hydration. As a result, the compressive strength improved and enhanced. Higher compressive strength values were obtained for OPC cement by increasing the polymer concentration when compared with 


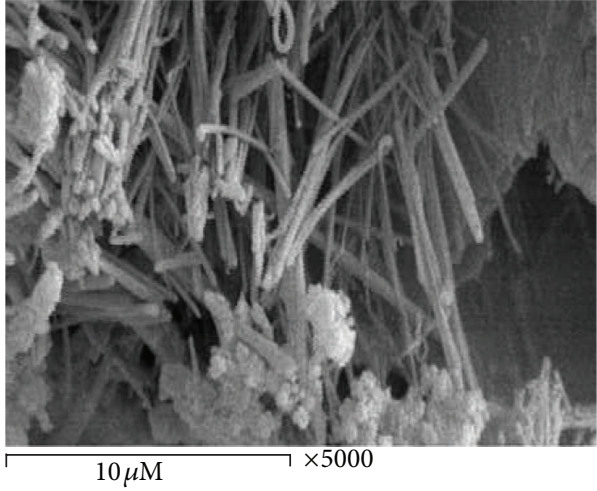

(a)

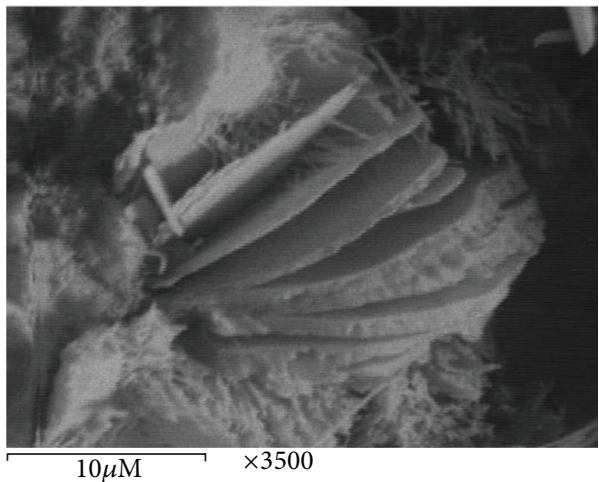

(c)

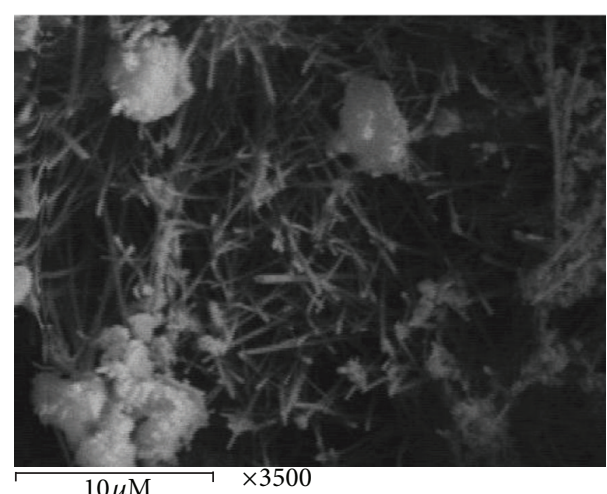

(b)

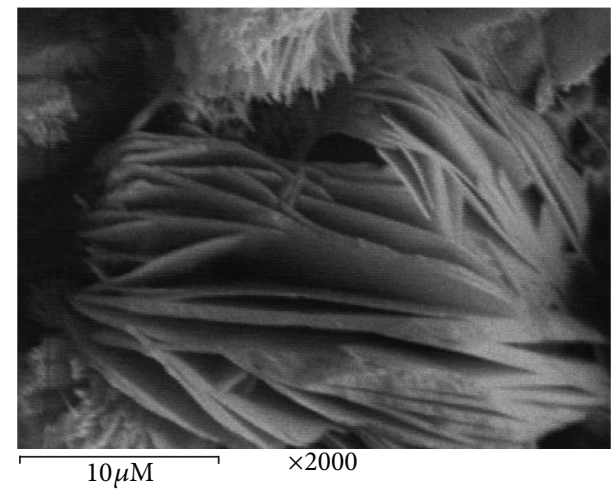

(d)

Figure 9: The SEM micrographs of The OPC pastes (a) premixed with $1 \%, 3 \%$ and $5 \%$ of HBPAE ((b), (c), and (d)) hydrated upto 28 days.

those of the blank samples at all curing periods, except at the first 24 hours of hydration. That behavior was to some extent due to both of the high activation effect of the hyperbranched poly amide-ester at later stages and the decrease of the apparent porosity which was resulted from further increase of the hydration products. Furthermore, the dispersing effect of the hyperbranched polymers/cement pastes improved the workability of such pastes. Therefore, an enhancement of the compressive strength was obtained. The SEM images of the OPC cement pastes (a) premixed with $1 \%, 3 \%$ and $5 \%$ of $\operatorname{HBPAE}((\mathrm{b}),(\mathrm{c})$, and (d)) are shown in Figure 9.

Generally, the needle-like crystals of ettringite phase $\left(\mathrm{C}_{3} \mathrm{~A} \cdot 3 \mathrm{CaSO}_{4} \cdot 32 \mathrm{H}_{2} \mathrm{O}\right)$ that formed due to the hydration reaction of $\mathrm{C}_{3} \mathrm{~A}$ with gypsum $\left(\mathrm{CaSO}_{4} \cdot 2 \mathrm{H}_{2} \mathrm{O}\right)$ in presence of water were clearly detected for OPC pastes (a). This phase decreased in presence of $1 \%$ HBPAE (b) while it completely disappeared with $3 \%$ and 5\% HBPAE ((c), (d)), respectively. This was due to the conversion of ettringite to monosulphate phase $\left(\mathrm{C}_{3} \mathrm{~A} \cdot \mathrm{CaSO}_{4} \cdot 12 \mathrm{H}_{2} \mathrm{O}\right)$. This indicated a better hydration of cement phases in its presence. The HBPAE also affected the morphology of Portlandite or $\mathrm{Ca}(\mathrm{OH})_{2}$ and $\mathrm{CSH}$ phases, resulting from the hydration of $\mathrm{C}_{3} \mathrm{~S}$ and/or $\beta-\mathrm{C}_{2} \mathrm{~S}$ phases of the cement, where the $\mathrm{Ca}(\mathrm{OH})_{2}$ crystals represent the weak phase in the binder matrix and the strengthening by both polymers improved the overall strength development of the binder matrix [30,31]. This in turn was reflected positively on the specific characteristics of the cement, particularly the mechanical strength. On the other side, the phases that formed with both types of polymers were the same as with the pure OPC pastes but with different morphologies and crystallinities, and well-developed crystals were noted with $5 \%$ due the dispersion effect where the crystals were larger, condensed, and more compacted.

\section{Conclusion}

The fundamental extraordinary desirable properties of the dendritic polymers have been demonstrated by using hyperbranched poly amide-ester as cement admixtures. Hyperbranched poly amide-ester which ended with $-\mathrm{OH}$ groups can be synthesized by pseudo-one-step process between pentaerithritol and $\mathrm{AB}_{n}$ prepolymerized monomer obtained by the reaction of maleic anhydride and diethanolamine in the presence of $\mathrm{p}$-toluene sulfonic acid as catalyst. The prepared HBPAE reduced the w/c ratio for OPC cement pastes compared to the blank. Therefore, it can be used as a waterreducing agent or a cement admixture. The HBPAE activates the cement phases and improves the rate of hydration. Also, the combined water content and the compressive strength were improved and enhanced by using HBPAE at all curing ages of hydration particularly at later stages. The SEM images showed that the addition of the HBPAE to cement did not affect the OPC hydrates, but it only affected the physical state, shape, morphology, and crystallinity of the formed hydrates. 


\section{Acknowledgments}

The authors are grateful to the members of the Egyptian Petroleum Research Institute.

\section{References}

[1] S. Wang, S. Tateyama, D. Kaneko, S. Ohki, and T. Kaneko, "Synthesis of well-defined hyperbranched polymers bio-based on multifunctional phenolic acids and their structure-thermal property relationships," Polymer Degradation and Stability, vol. 96, no. 12, pp. 2048-2054, 2011.

[2] M. Fischer and F. Vögtle, "Dendrimers: from design to application-a progress report," Angewandte Chemie International Edition, vol. 38, pp. 884-905, 1999.

[3] Y. Bao, J. He, and Y. Li, "Synthesis of novel hyperbranched poly(ester-amide)s based on acidic and basic amino acids via "AD + CBB" couple-monomer approach," Polymer, vol. 53, pp. 145-152, 2012.

[4] Z. Li, W. Wu, C. Ye, J. Qin, and Z. Li, "New main-chain hyperbranched polymers: facile synthesis, structural control, and second-order nonlinear optical properties," Polymer, vol. 53, pp. 153-160, 2012.

[5] T. Wang, M. Li, H. Gao, and Y. Wu, "Nanoparticle carriers based on copolymers of poly( $\varepsilon$-caprolactone) and hyperbranched polymers for drug delivery," Journal of Colloid and Interface Science, vol. 353, no. 1, pp. 107-115, 2011.

[6] S. S. Mahapatra, S. K. Yadav, and J. W. Cho, "Nanostructured hyperbranched polyurethane elastomer hybrids that incorporate polyhedral oligosilsesquioxane," Reactive and Functional Polymers, vol. 72, pp. 227-232, 2012.

[7] J. M. J. Fréchet, "Functional polymers and dendrimers: reactivity, molecular architecture, and interfacial energy," Science, vol. 263, no. 5154, pp. 1710-1715, 1994.

[8] B. I. Voit, "Dendritic polymers: from aesthetic macromolecules to commercially interesting materials," Acta Polymerica, vol. 46, pp. 87-99, 1995.

[9] K. M. Lee, J. W. Woo, B. C. Jee et al., "Effect of cross-linking agent and heteropolyacid (HPA) contents on physicochemical characteristics of covalently cross-linked sulfonated poly(ether ether ketone)/HPAs composite membranes for water electrolysis," Journal of Industrial and Engineering Chemistry, vol. 17, p. 657, 2011.

[10] S. Y. Jang and S. H. Han, "Preparation of high styrenic sulfonated polySEPS/clay composite film for proton exchange membranes (PEMs)," Journal of Industrial and Engineering Chemistry, vol. 18, no. 4, pp. 1280-1285, 2012.

[11] D. J. Kim, H. Y. Hwang, S. B. Jung, and S. Y. Nam, "Sulfonated poly(arylene ether sulfone)/Laponite-SO3H composite membrane for direct methanol fuel cell," Journal of Industrial and Engineering Chemistry, vol. 18, p. 556, 2012.

[12] S. Kwon, H. Kim, J. W. Ha, and S. Y. Lee, "Prevention of protein and polymeric nanoparticles adsorption using perfluoropolyether," Journal of Industrial and Engineering Chemistry, vol. 17, no. 2, pp. 259-263, 2011.

[13] M. Ramli and A. A. Tabassi, "Effects of polymer modification on the permeability of cement mortars under different curing conditions: a correlational study that includes pore distributions, water absorption and compressive strength," Construction and Building Materials, vol. 28, pp. 561-570, 2012.

[14] F. Pacheco-Torgal, Abdollahnejad, A. F. A. Camões, M. Jamshidi, and Y. Ding, "Durability of alkali-activated binders: a clear advantage over Portland cement or an unproven issue?" Construction and Building Materials, vol. 30, pp. 400-405, 2012.

[15] Y. Ohama, "Polymer-based admixtures," Cement and Concrete Composites, vol. 20, no. 2-3, pp. 189-212, 1998.

[16] F. M. Kılınçkale and G. G. Dogan, "Performance of concretes produced with superplasticizer," Journal of Applied Polymer Science, vol. 103, pp. 3214-3219, 2006.

[17] A. Kapelko, "The possibility of adjusting concrete mixtures "fluidity by means of super plasticizer SNF",' in Archives of Civil and Mechanical Engineering, 6th edition, 2006.

[18] I. Papayianni, G. Tsohos, N. Oikonomou, and P. Mavria, "Influence of superplasticizer type and mix design parameters on the performance of them in concrete mixtures," Cement and Concrete Composites, vol. 27, no. 2, pp. 217-222, 2005.

[19] D. W. Fowler, "Polymers in concrete: a vision for the 21st century," Cement and Concrete Composites, vol. 21, no. 5-6, pp. 449452, 1999.

[20] B. Chatveera and P. Lertwattanaruk, "Evaluation of sulfate resistance of cement mortars containing black rice husk ash," Journal of Environmental Management, vol. 90, no. 3, pp. 14351441, 2009.

[21] U. S. Yilmaza and H. Turken, "The effects of various curing materials on the compressive strength characteristic of the concretes produced with multiple chemical admixtures," Scientia Iranica A, vol. 19, pp. 77-83, 2012.

[22] A. Amin, H. H. M. Darweesh, S. M. M. Morsi, and M. M. H. Ayoub, "Effect of phthalic anhydride-based hyperbranched polyesteramide on cement characteristics," Journal of Applied Polymer Science, vol. 120, no. 5, pp. 3054-3064, 2011.

[23] ASTM C 187-86, American Standard Test Method, 1993.

[24] STM C 191-92, American Standard Test Method, 1993.

[25] STM C 191, Standard Test Methods for Time of Setting of Hydraulic Cement by Vicat Needle, 2008.

[26] ASTM C 170-90, American Standard Test Method, 1993.

[27] P. C. Hewlett, Lea's Chemistry of Cement and Concrete, John Wiley \& Sons, New York, NY, USA, 4th edition, 1998.

[28] C. Qing-Hua, C. Rong-Guo, X. Li-Ren, Q. Qing-Rong, and Z. Wen-Gong, "Hyperbranched poly(amide-ester) mildly synthesized and its characterization," Jiegou Huaxue, vol. 27, no. 7, pp. $877-883,2008$.

[29] S. Hanehara and K. Yamada, "Interaction between cement and chemical admixture from the point of cement hydration, absorption behaviour of admixture, and paste rheology," $\mathrm{Ce}$ ment and Concrete Research, vol. 29, no. 8, pp. 1159-1165, 1999.

[30] E. Knapen and D. Van Gemert, "Cement hydration and microstructure formation in the presence of water-soluble polymers," Cement and Concrete Research, vol. 39, no. 1, pp. 6$13,2009$.

[31] M. M. H. Ayoub, H. E. Nasr, and H. H. M. Darweesh, "Characterization and utilization of polystyrene and polyacrylamidegraft-methoxypolyethylene as cement admixtures," Polymer, vol. 45, no. 12, pp. 1307-1315, 2006. 

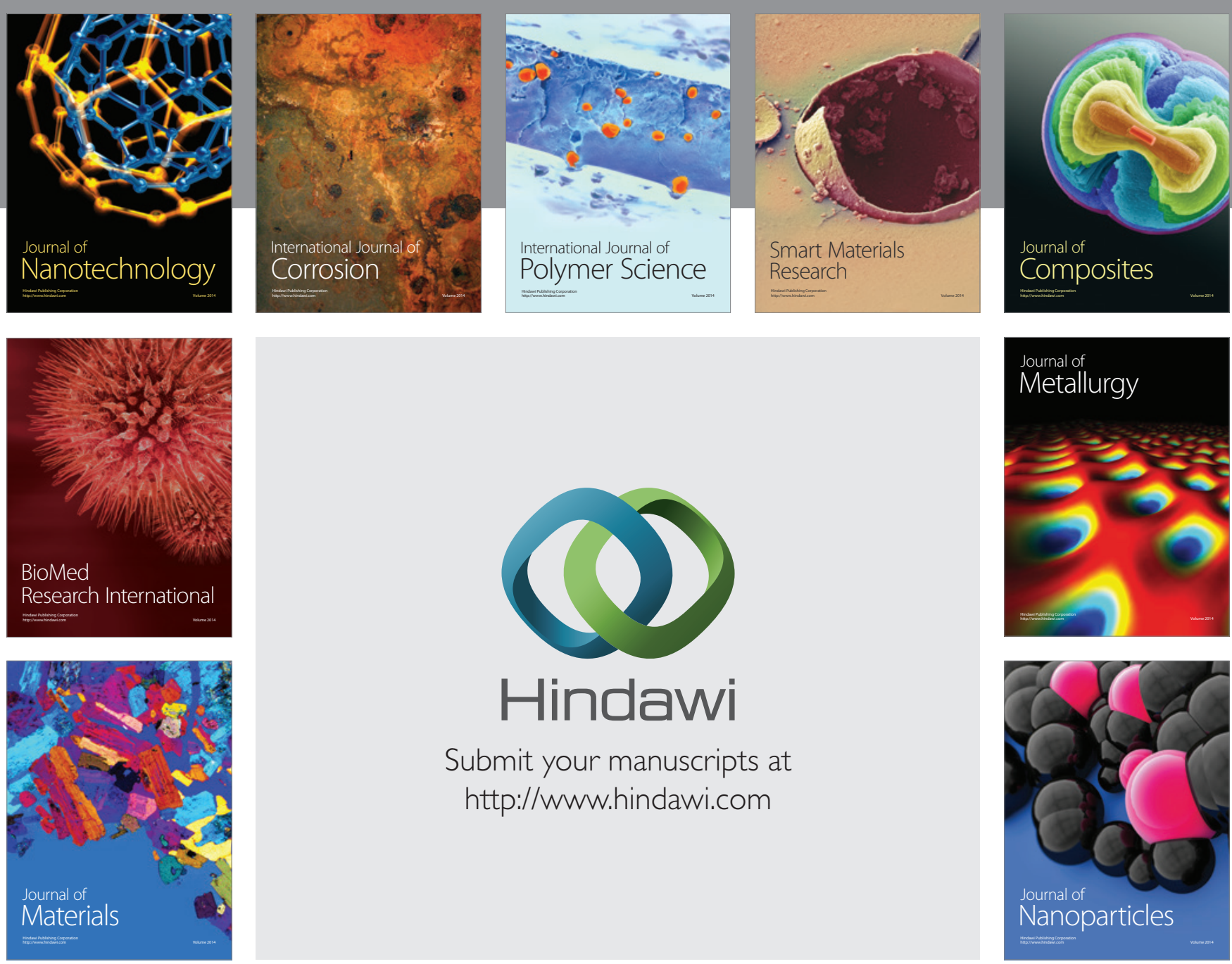

Submit your manuscripts at http://www.hindawi.com
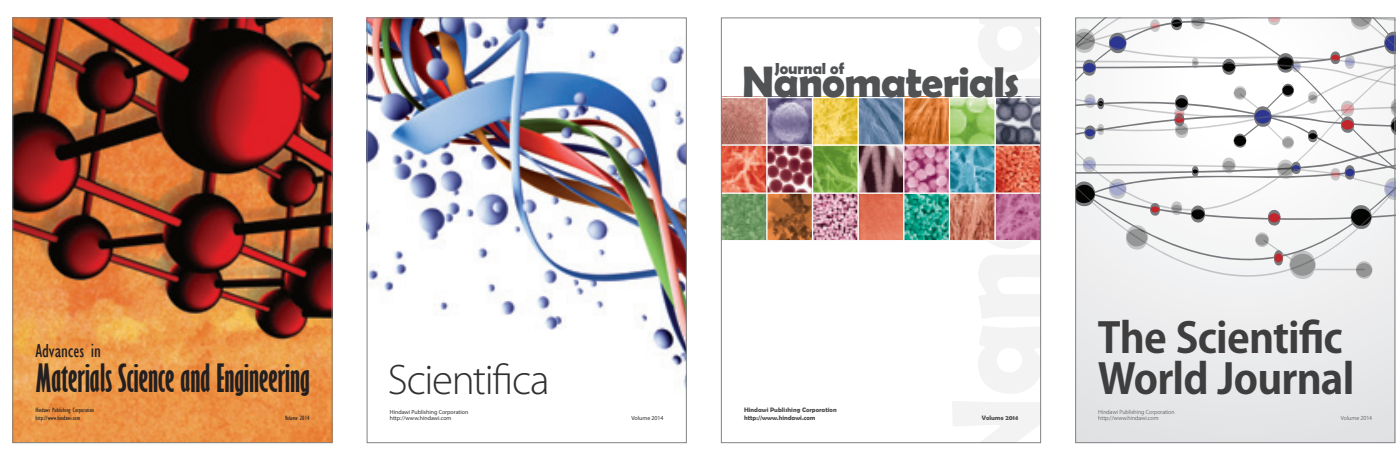

\section{The Scientific World Journal}
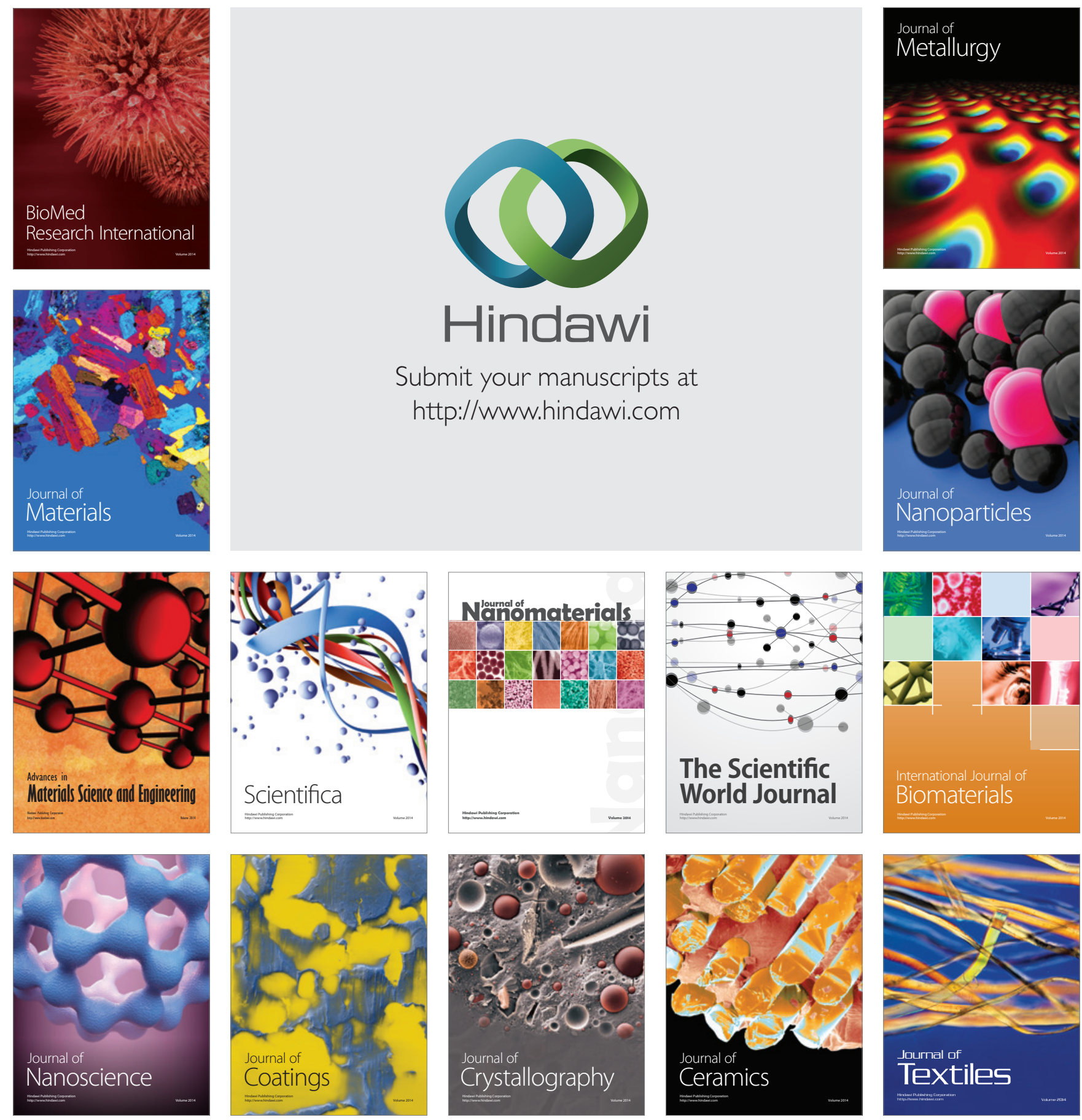